\title{
Factors associated with positive attitudes toward organ donation in Arab Americans
}

Padela AI, Rasheed S, Warren GJW, Choi H, Mathur AK. Factors
associated with positive attitudes toward organ donation in Arab
Americans.
Clin Transplant 2011: 25: 800-808. @ 2010 John Wiley \& Sons A/S.

Abstract: Background: The demand for transplantable organ continues to exceed supply, particularly in minority patient populations. We explored the factors influencing organ donation attitude within the Arab American community.

Methods: Secondary data analysis from a face-to-face survey administered in late 2003 to 1016 adults from a representative population-based sample on Greater Detroit Arab Americans.

Results: Christian Arab Americans were more likely than Muslim Arab Americans, and women more than men, to believe organ donation after death was justifiable. Higher educational attainment and income, as well as greater acculturation into American society, were associated with greater odds of believing organ donation to be justified. Self-reported health status and level of psychological distress and health insurance status were not associated with beliefs about organ donation.

Conclusions: A multifaceted approach toward increasing organ donation rates in this growing population requires targeted community-health care system collaborations involving religious and civic leaders using Arabic language and culturally sensitive media.

Summary: Arab Americans represent a growing population about which little is known in regard to organ donation and transplantation. This population is not specifically captured within national and local transplantation databases, and little empiric work has assessed attitudes and barriers toward organ donation and transplantation within this community. Our work represents the first to use a representative population-based sample to explore the modifiable and non-modifiable characteristics of those who believe cadaveric organ donation to be justified.

\author{
Aasim I. Padela ${ }^{\mathrm{a}, \mathrm{b}}$, Shoaib \\ Rasheed $^{\mathrm{b}}$, Gareth J. W. Warren ${ }^{\mathrm{b}, \mathrm{c}}$, \\ Hwajung Choi ${ }^{\mathrm{b}}$ and Amit K. \\ Mathur $^{\mathrm{d}}$
}

aDepartment of Emergency Medicine, ${ }^{\text {b Robert }}$ Wood Johnson Foundation Clinical Scholars Program, Department of Internal Medicine, Departments of 'Urology and 'S Surgery, University of Michigan, Ann Arbor MI, USA

Key words: Arab Americans - beliefs cadaveric organ donation - minority organ donation - Muslim

Corresponding author: Aasim I. Padela, MD, MS, Robert Wood Johnson Clinical Scholars Program, 6312 Med Sci Bldg I, 1150 W. Medical Center Drive, Ann Arbor, Ml 48109-5604, USA. Tel.: 734647 4844; fax: 734647 3301; e-mail: aasim@umich.edu

Conflict of interest: None.

Accepted for publication 2 November 2010
The disparity between organ supply and organ demand continues to affect thousands of individuals with end-organ failure awaiting transplantation in the United States. Efforts to promote organ donation have been the focus of organ procurement organizations (OPOs), research initiatives, and significant federal support through the Health Resources and Services Administration (HRSA) and Organ Donation and Transplant Collaboratives. These donation initiatives have increased organ donation rates overall, yet several minority populations have less than expected numbers of deceased and living donors annually $(1,2)$. The factors influencing minority attitudes toward organ donation and their willingness to be organ donors are complex (3-6). Studies of the
African American population have cited religious beliefs, mistrust of health care providers, and perceptions of the health care system in general, as factors affecting decisions involving organ donation (7-10). In the Hispanic and Asian populations, a lack of public awareness of transplantation has been identified as a significant barrier toward organ donation $(11,12)$. Socioeconomic and health status, as well as health literacy, also influence the decision to register for, or to donate, organs $(3,4,9,13-17)$. Despite these efforts to identify the factors affecting organ donation decisions within larger ethnic minority groups, the influences upon Arab American attitudes toward organ donation have not been delineated. 
Arab Americans represent a growing US ethnic minority group numbering more than 2 million people that is diverse with respect to national origin and religious affiliation $(18,19)$. Systematic empirical research on the prevalence and relative burden of disease within this community has been scant and methodologically challenging giving the lack of capture of Arab ethnicity within most national databases (20). The same issue plagues organ transplantation databases where identification of this ethnic group is difficult, and thus, little is known regarding baseline rates of organ donation or transplant within this community $(21,22)$. The extant medical literature does offer some data with respect to disease states that have bearing upon end-organ failure and organ transplant. The prevalence of hypertension among Arab Americans is between 13\% and $20 \%$ comparable to that of non-Hispanic whites, yet the prevalence of other risk factors for cardiovascular disease is higher than that of the general US population (20, 23-26). Further ageadjusted disease incidences for liver and kidney cancers are higher in Arab Americans when compared to non-Arab whites (27). These data suggest that Arab Americans may represent a community where the need for organs is significant; however, systematic research is necessary to support such claims.

With respect to organ donation, research within the Arab world has identified religious beliefs, mistrust of the health care system, poor health care infrastructure, and the lack of awareness of need as barriers to organ donation (28-33). However, it is unclear whether these attitudes are shared by those who have emigrated to the United States or are present in succeeding US-born generations. Additionally, the influence of acculturation and demographics upon decisions to donate organs has not been systematically investigated.

Approximately 490000 Arabs reside in Michigan where they comprise the state's third largest ethnic population $(18,34)$. We investigated this populations' attitudes toward organ donation through use of the 2003 Detroit Arab American Study (DAAS) (35). We explored the association between socioeconomic status, religion, health status, and acculturation with attitudes toward organ donation after death.

Drawing from the literature about Arabs outside of the United States, we proceeded with several hypotheses. Studies of Muslim Arabs reveal that those willing to donate organs themselves, or to consent to donating family member's organs, are religiously motivated (32, 36-38). However, research within non-Arab Muslim communities in the United Kingdom and Turkey has found cultural and religious beliefs to be barriers for organ donation $(33,39,40)$. Given the ambiguous nature of organ donation within Islamic bioethics and law, we hypothesized that Muslim Arabs would hold more negative attitudes toward organ donation than Christian Arabs (41-43).

Similarly, we posited that people with more education have greater access to organ procurement messaging and thus have less fear of the organ donation process $(13,44)$. Hence, respondents with greater educational attainment would find organ donation to be more justified. Similarly, we felt that Arab males and those with higher income would hold more positive attitudes toward organ donation echoing findings from a large population-based survey of Americans and Europeans (45).

Lastly, we hypothesized that more acculturated Arab Americans would feel organ donation to be justifiable more so than less acculturated members of the community. As acculturation within a society may be proxy for "feeling at home" in one's new residence, a communitarian ethic may arise where one would be more inclined to justify organ donation. Additionally, language proficiency subdomains of acculturation indices correlate with educational level, and given the argument earlier regarding educational level, those more acculturated by these measures may hold more positive attitudes. Furthermore, acculturation may be a marker for less distrust and/ or less perceived discrimination within society, thereby allaying fears toward organ donation processes in specific and the health care system in general.

Improved understanding of factors influencing attitudes toward organ donation in this group may contribute to the creation of culturally sensitive targeted interventions to increase donor registration, living donation, and transplant evaluation of potential candidates from these, and other, minority communities.

\section{Materials and methods}

Participants and data collection

The DAAS is a representative population-based survey conducted from July to December 2003 of all adults of Arab descent living in the Greater Detroit area, which is home to one of the largest and most highly concentrated Arab American communities in the United States $(18,19,34,35)$. Nearly $80 \%$ of the Arabs living in the state reside 
in the three counties sampled by DAAS (18). It was a companion study to the Detroit Area Study, which has been conducted by the University of Michigan annually since 1951 (46). Designed through a community-academic collaboration with several Arab community organizations, the survey comprised face-to-face interviews. A dual-frame probability sample design was utilized, with an area probability frame used to select area segments from the year 2000 census tracts in which $10 \%$ or more of persons self-classified as of Arab or Chaldean ancestry, and a list frame for selecting housing units from mailing and membership lists of 13 Arab- and Chaldean-American organizations. The area probability sample component was based on a three-stage sample design, a primary-stage sample of area segment units, followed by a second-stage sample of housing units within area segments and then random selection of one eligible adult from each household. Within the list frame, a systematic random sample of individual addresses was utilized with random selection of one eligible adult respondent in each household. A total of 1389 eligible households were identified, from which 1016 adults completed the study interview (73\% participation rate). The DAAS was approved by the University of Michigan Institutional Review Board $(47,48)$.

\section{Measures}

Independent variables. Our independent variables involved three domains: health status, acculturation, and demographics. Health status was assessed by two measures: the Short Form-1 (SF-1), a single-item measure of health status that has been shown to be an independent predictor of future mortality even after adjusting for baseline physical health status and life style, and the Kessler Psychological Distress Scale (K10) (49, 50). The $\mathrm{K} 10$ is a validated population screening tool for anxiety and depressive disorders comparable to the General Health Questionnaire (GHQ) and Medical Outcomes Study Short-Form 12-Item Health Survey (SF-12) (51-53). Higher scores on the K10 denote higher likelihood for having a mood or anxiety disorder, and respondents are screened into low-, medium-, and high-risk pools (54). The Cronbach's $\alpha$ in our sample was 0.89 . We computed a Kessler score for each respondent, and Markov chain imputation was used if at least seven of the 10 questions were answered (55). Of the 1016 respondents, 1005 had responded to at least seven of 10 items. Acculturation measures were constructed from exploratory factor analyses using all questions conceptually related to acculturation within DAAS (48, 56). The factor analysis suggested two factors in the acculturation domain: English proficiency and a second composite measure of length of residence in the United States and citizenship status. English proficiency was obtained from a weighted score based on three items assessing comfort with speaking, reading, and writing in English, and the weighted score ranged from -2.5 to 0.8 . The second acculturation measure comprised an index measure being the sum of two indicator variables: (i) length of residence in United States is greater than $10 \mathrm{yr}$ and (ii) US citizenship status. The demographics category included sex, age $(18-29,30-44,45-59,60+)$, religious affiliation, educational level (less than high school, college level, and advanced degree), household income (less than $\$ 30000$, between $\$ 30000-75000$, and over $\$ 75000)$, and health insurance status.

Outcome measure. Our primary outcome was attitude toward organ donation. This variable was measured using the following survey question: "Do you think organ donation after death can always be justified, never be justified or somewhere in-between?" The responses were initially on a 1-10 scale, which was collapsed into three categories as most respondents had answered at either end of the scale. Of the 1016 respondents, 1011 answered the question about attitude toward organ donation with $20 \%$ feeling organ donation after death was never justifiable, $35 \%$ always, and $46 \%$ responded somewhere in-between.

\section{Data analysis}

Descriptive statistics including means and proportions were calculated without survey weights. For all other analyses, survey weights incorporating sample selection, non-response, and post-stratification factors were applied to each respondent, and analysis was conducted using a single-unit scaled strategy for variance estimates. Analyses were conducted using STATA version 11 (STATA Corp., College Station, TX, USA). Ordered logistic regression models were employed to test the association between justification of organ donation after death and all independent variables. Bivariate analyses were conducted for all independent variables to assess their effect on whether respondents felt organ donation was justified, and unadjusted odds ratios (OD) were calculated. This was followed by three separate multivariate ordered logistic regression analyses. The first model analyzed the association between all demographic factors and justification of organ 
donation. The next model tested the associations between the two acculturation measures and organ donation attitude using a multivariate ordered logistic regression equations adjusting for demographics. Similarly, the final model tested the association between the two health status markers and attitude toward organ donation adjusting for demographics.

\section{Results}

\section{Respondent characteristics}

The mean age of the 1016 respondents was $43.6 \mathrm{yr}$ $(\mathrm{SD}=16.5$, range $=18-88)$. Fifty-four percent of the respondents were women, and $58 \%$ were Christians. Most respondents had health insurance coverage $(83 \%)$, and there was a wide variance in educational level and household income (Table 1).

\section{Association between demographics and positive} attitudes toward organ donation after death

Demographic factors were significant predictors of attitudes toward organ donation. In bivariate analyses, being male (OR 0.79, 95\% confidence interval
[CI] 0.63-0.98) and Muslim (OR 0.50, CI 0.37-0.67) were significantly associated with lower odds of believing organ donation after death to be justifiable. More positive attitudes toward organ donation were predicted by higher income (income between $\$ 30000$ and 75000 OR 2.07, CI 1.43-3.00; $>\$ 75000$ OR 2.40, CI 1.77-3.23), greater educational attainment (some college OR 1.97, CI 1.492.60; advanced degree OR 2.24, CI 1.36-3.70), and having health insurance (OR 1.98, CI 1.28-3.05).

In a multivariate model accounting for all demographics categories, these associations largely continued to hold. Men and Muslims had lower adjusted odds of believing organ donation after death to be justifiable (OR 0.76, CI 0.61-0.96, and OR 0.65 , CI 0.47-0.91, respectively). Individuals with household income $>\$ 30000$ were significantly more likely to have positive attitudes toward organ donation compared to those with household income $<\$ 30000$ (OR 1.50, CI 1.01-2.25). Similarly, the positive association between educational attainment and believing organ donation to be justifiable continued to be statistically significant for those with some college education (OR 1.74, CI 1.35-2.24) but not significant for those with advanced degrees. Insurance status was not

Table 1. Sociodemographic factors associated with positive attitudes toward cadaveric organ donation among Arab Americans

\begin{tabular}{|c|c|c|c|}
\hline & & Bivariate $^{a}$ & $\begin{array}{l}\text { Multivariate }^{b} \\
(\mathrm{n}=840)\end{array}$ \\
\hline & $\mathrm{N}(\%)$ & $\begin{array}{l}\text { Odds ratio } \\
\text { (95\% confidence interval) }\end{array}$ & $\begin{array}{l}\text { Odds ratio } \\
\text { ( } 95 \% \text { confidence interval) }\end{array}$ \\
\hline \multicolumn{4}{|l|}{ Gender } \\
\hline Female & $538(54)$ & 1.00 Reference & 1.00 Reference \\
\hline Male & $466(46)$ & $0.79(0.63-0.98)^{\star}$ & $0.76(0.61-0.96)^{\star}$ \\
\hline \multicolumn{4}{|l|}{ Religion } \\
\hline Christian & $579(58)$ & 1.00 Reference & 1.00 Reference \\
\hline Muslim & $422(42)$ & $0.50(0.37-0.67)^{\star \star \star}$ & $0.65(0.47-0.91)^{\star *}$ \\
\hline \multicolumn{4}{|l|}{ Age (yr) } \\
\hline $18-29$ & $222(22)$ & 1.00 Reference & 1.00 Reference \\
\hline $30-44$ & 357 (35) & $0.85(0.64-1.13)$ & $0.90(0.64-1.25)$ \\
\hline $45-59$ & $219(22)$ & $1.56(0.98-2.50)$ & $1.60(1.01-2.53)^{\star}$ \\
\hline $60+$ & $220(22)$ & $0.86(0.54-1.37)$ & $0.93(0.51-1.71)$ \\
\hline \multicolumn{4}{|l|}{ Income } \\
\hline$<30000$ & $313(36)$ & 1.00 Reference & 1.00 Reference \\
\hline $30000-75000$ & $257(29)$ & $2.07(1.43-3.00)^{\star \star \star}$ & $1.50(1.01-2.25)^{\star}$ \\
\hline $75000+$ & $304(35)$ & $2.40(1.77-3.23)^{\star \star \star}$ & $1.48(0.95-2.29)$ \\
\hline \multicolumn{4}{|l|}{ Education } \\
\hline High school or less & $453(45)$ & 1.00 Reference & 1.00 Reference \\
\hline Some college & $439(44)$ & $1.97(1.49-2.60)^{\star \star \star}$ & $1.74(1.35-2.24)^{\star \star \star}$ \\
\hline Advanced degree & $113(11)$ & $2.24(1.36-3.69)^{\star \star}$ & $1.75(0.87-3.50)$ \\
\hline \multicolumn{4}{|l|}{ Health insurance } \\
\hline Insured & $839(83)$ & $1.98(1.28-3.05)^{\star \star}$ & $1.44(0.87-2.39)$ \\
\hline Uninsured & $171(17)$ & 1.00 Reference & 1.00 Reference \\
\hline
\end{tabular}

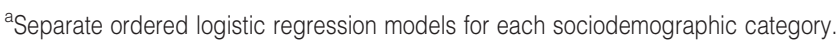

${ }^{\mathrm{b}} \mathrm{A}$ single multivariate ordered logistic regression model controlled for gender, religion, age, income, education, and health insurance.

${ }^{*} p<0.05,{ }^{* *} p<0.01,{ }^{* * *} p<0.001$. 
Table 2. Health status and psychological distress markers and their association with positive attitudes toward cadaveric organ donation in Arab Americans

\begin{tabular}{lll}
\hline & Unadjusted & \\
\hline $\begin{array}{l}\text { Overall health } \\
\text { Poor }\end{array}$ & $\begin{array}{l}\text { Adjusted }^{\mathrm{b}} \\
(\mathrm{n}=828)\end{array}$ \\
Fair & 1.00 Reference & 1.00 Reference \\
Good & $0.51(0.18-1.46)$ & $0.52(0.16-1.70)$ \\
Very good & $0.68(0.26-1.78)$ & $0.52(0.17-1.60)$ \\
Excellent & $0.87(0.32-2.31)$ & $0.62(0.19-2.12)$ \\
Kessler Psychological Distress Scale & $0.50(0.15-1.67)$ \\
Low risk & 1.00 Reference & 1.00 Reference \\
Medium risk & $1.23(0.86-1.75)$ & $1.04(0.68-1.57)$ \\
High risk & $1.14(0.58-2.24)$ & $1.05(0.49-2.25)$ \\
\hline
\end{tabular}

aSeparate ordered logistic regression models for each marker of health status. ${ }^{b}$ Multivariate ordered logistic regression models controlling for gender, religion, age, income, educational attainment, and health insurance status.

significantly associated with beliefs around organ donation in multivariate models (Table 1).

\section{Health status}

Three percent of the respondents reported poor health, and $28 \%$ reported excellent health, with $13 \%, 26 \%$, and $30 \%$, respectively, reporting fair, good, and very good health. While $18 \%, 73 \%$, and $8 \%$ of respondents screened for low, medium, and high risk of anxiety or mood disorder according to the K10. Both of these health status markers were not associated with attitudes toward organ donation in either bivariate or multivariate models (Table 2).

\section{Acculturation}

Acculturation was significantly associated with attitudes toward organ donation in adjusted models. Being a US citizen and/or having resided in the United States for greater than $10 \mathrm{yr}$ significantly increased the odds of believing organ donation after death to be justifiable (OR 1.61, CI 0.892.90), while having both characteristics further strengthened this association (OR 1.69, CI 1.042.74). Increasing English proficiency, the second measure of acculturation, was also positively associated with believing organ donation after death to be justifiable in both unadjusted and adjusted models (OR 1.45, CI 1.26-1.67 and OR 1.29 , CI 1.08-1.54, respectively) (Table 3 ).

\section{Discussion}

This study represents a first look into Arab American attitudes toward organ donation. Using
Table 3. Measures of acculturation and their association with positive attitudes toward cadaveric organ donation Among Arab Americans

\begin{tabular}{lcc}
\hline & $\begin{array}{l}\text { Unadjusted }^{\mathrm{a}} \\
(\mathrm{n}=1003)\end{array}$ & $\begin{array}{c}\text { Adjusted } \\
(\mathrm{n}=833)\end{array}$ \\
\hline Acculturation 1 Index & & \\
0 & 1.00 Reference & 1.00 Reference \\
1 & $1.72(0.96-3.11)$ & $1.61^{*}(0.90-2.91)$ \\
2 & $2.17^{* *}(1.36-3.47)$ & $1.69^{*}(1.04-2.74)$ \\
Acculturation $_{2 \text { Score }}$ & $1.45^{* * *}(1.26-1.67)$ & $1.29^{* *}(1.08-1.54)$ \\
\hline
\end{tabular}

${ }^{a}$ Multivariate ordered logistic regression model including both measures of acculturation.

${ }^{b}$ Multivariate ordered logistic regression model using both measures of acculturation and controlling for gender, religion, age, income, educational attainment, and health insurance status.

${ }^{c}$ Acculturation: being a US citizen, living in the US for $10 \mathrm{yr}$. One point was given for a positive answer to each question with a maximum of two points.

'Literacy: speak, read, write English. One point was given for a positive answer to each question with a maximum of three points.

${ }^{*} p<0.05,{ }^{* *} p<0.01,{ }^{* * *} p<0.001$

a population-based representative sample, our study characterizes some of the modifiable and non-modifiable factors that influence attitudes toward organ donation in the Arab American population. Christian Arab Americans were more likely than Muslim Arab Americans, and women more than men, to believe organ donation after death was justifiable. Higher educational attainment and income were also associated with greater odds of believing organ donation to be justified. Furthermore, higher acculturation into US society, in both English proficiency and demographic subdomains, was associated with a greater odds of believing organ donation to be justified. However, after adjusting for sociodemographic factors, health insurance status, self-reported health status, and level of psychological distress were not associated with beliefs about organ donation. These findings largely concur with our hypotheses, are supported by the literature on factors associated with organ donation in minority communities, and have several implications for educational initiatives to increase organ donation in this community.

Religious affiliation has previously been identified as a factor that plays a role in the decision to register as an organ donor $(5,6,13,14,17,57-60)$. In our sample, Muslim Arab Americans were less likely than Christian Arab Americans to find organ donation after death to be justified. This finding is supported by several studies that have shown the reluctance of Muslim Arabs to be organ donors. In Saudi Arabia and Qatar, countries with $>90 \%$ Muslim populations, only a minority carry organ donation cards or are willing to donate their organs, and in Saudi and Israeli Arab samples, those who refused consenting to organ donation 
cited religious reasons (32, 36-38). Although many Islamic scholars in the Arab world have sanctioned organ donation, residual ambiguity remains making decisions to donate complicated within our group and abroad $(41,43)$. Several experts have engaged local religious leaders in Middle Eastern communities to increase the awareness of organ donation and transplantation. Similar campaigns to educate and then elicit support from religious leaders within the Arab American Muslim community in the United States may aid in increasing organ donation rates (30, 61-64). Indeed, a recent focus group study of health care attitudes among Arab Americans noted the need for culturally, linguistically, and religiously sensitive health care partnerships involving community leaders to overcome barriers and mistrust within this community (65).

Our data demonstrate that higher income and greater educational attainment are associated with more positive attitudes toward organ donation. This correlation has been noted by other investigators and is believed to be attributable to increased access to organ donation materials and messaging by individuals within higher economic strata $(1,13,17,44,58)$. Evidence for this assertion is further strengthened by our finding that higher acculturation correlated with more positive attitudes toward organ donation. Hence, those with limited English language proficiency may not be effectively targeted by current organ procurement campaigns or possess decreased trust of the health care system. OPOs and advocates of organ transplantation may benefit from partnering with Arab community organizations to provide culturally competent and religiously sensitive materials in Arabic media to increase awareness and allay fears around organ donation. These types of interventions have been employed successfully in the National Minority Organ and Tissue Transplant Education Program $(64,66)$.

Our analysis of the Arab American community inherently begs comparison to findings in other ethnic groups. The sociodemographic predictors we have identified are also relevant in a broader population context. Boulware and colleagues surveyed a multiethnic population in Maryland and identified socioeconomic status, health status, and religious beliefs to affect willingness toward cadaveric organ donation (67). Significant effort has been dedicated to determining how spiritual and religious beliefs influence attitudes toward organ donation, as these beliefs play a role in several minority groups, including African Americans, Hispanics, and Asian Americans, underscoring the importance of being sensitive to these beliefs in organ donation and transplant advocacy (5, 57, 59). Studies comparing differential effects of these predictors on the willingness to donate across different racial/ethnic groups are limited and do not include Arab Americans. However, this work does demonstrate the importance of educating patients and families about end-of-life care and enhancing trust in health care providers as means to allay fears about organ donation (4). Our study is unique in the organ donation literature because it demonstrates how acculturation may influence this decision, particularly as it relates to immigrant communities.

While utilizing the 2003 DAAS survey lends strength to our findings through representative sampling, the use of a publicly available deidentified dataset also introduces limitations. Most obviously, we are limited to the measures included within this survey that did not comprehensively assess health measures or attitudes toward organ donation. Personal perceptions of health status, as recorded using the K10 and SF-1 survey tools, did not have an appreciable effect on attitudes toward organ donation in our study. While both measures are validated, it is possible that more specific measures related to end-organ failure might have yielded a different association between health status and attitude toward organ donation.

Within the study construct, our outcome measure assesses attitudes toward organ donation after death as "justifiable." This connotes an ethical judgment regarding organ donation in general and may not necessarily measure one's willingness to donate their own or a relative's organs. Hence, one must be careful not to overgeneralize our findings. Additional investigations are necessary to fully understand the implications of our work; however, our findings lay a strong foundation for future surveys within the Arab American community. Lastly, our study was conducted within the Greater Detroit Arab American population, a community that has significant civic engagement and a long history dating back multiple generations. As our community may have more social capital and a higher socioeconomic status when compared with other Arab American communities, generalizing our findings to such smaller communities may not be possible $(68,69)$. However, precisely because of its long history and large numbers, our sample is arguably one of the most important Arab American communities, and one would expect that this established community would have a greater affinity toward organ donation than smaller communities where there are a greater number of immigrants and less ethnic density. Hence, the implications of our findings, e.g., acculturation influencing the 
attitudes toward organ donation, may be more significant in these smaller communities.

Our study has clear policy implications for the organ procurement and transplant community. The factors identified, and hypotheses proposed in this study, may be further developed using qualitative methods to understand how personal nuance, and family influence affect the processes of registering as a potential donor, or consenting to be an organ donor. Educational attainment and acculturation were strong predictors of positive attitudes toward organ donation, suggesting that promotion of organ donation should be initiated using culturally competent methods including the use of Arabic language, Arabic media, social networking, and partnering with Arab American community leaders. Targeted educational efforts aimed at health care providers serving the Arab American community may increase donor registration by improving awareness of transplantation and allaying fears regarding the process (28, 40, 70-77). A multifaceted approach toward increasing awareness in this growing population using targeted culturally competent interventions has the potential to increase the willingness of Arab Americans to become organ donors.

\section{Acknowledgements}

The authors thank Wayne Baker, Sally Howell, Ronald Stockton, Amaney Jamal, Ann Chih Linn, Andrew Shryock, and Mark Tessler, and the entire DAAS team along with its funders the Russell Sage and Andrew W. Mellon Foundations in originating and conducting the DAAS and making it publicly available for future researchers. We also acknowledge Michele Heisler, MD, MPA, for her mentorship, insightful comments, and support. The time-effort put forth by AIP, GW, HC, and SR was all funded by the Robert Wood Johnson Foundation Clinical Scholars Program.

\section{References}

1. Siminoff LA, Gordon N, Hewlett J, Arnold RM. Factors influencing families' consent for donation of solid organs for transplantation. JAMA 2001: 286: 71.

2. The Office of Minority Health, U.S. Department of Health \& Human Services. Organ Donation Data/ Statistics. Washington, DC: The Office of Minority Health, U.S. Department of Health \& Human Services, 2009.

3. Daniels DE, Smith K, Parks-Thomas T, GibBs D, RoBinson J. Organ and tissue donation: are minorities willing to donate? Ann Transplant 1998: 3: 22.

4. McNamara P, Guadagnoli E, Evanisko MJ et al. Correlates of support for organ donation among three ethnic groups. Clin Transplant 1999: 13(1 Pt 1): 45.

5. Davis C, Randhawa G. The influence of religion on organ donation and transplantation among the Black Caribbean and Black African population - a pilot study in the United Kingdom. Ethn Dis 2006: 16: 281.
6. Davis K, Holtzman S, Durand R, Decker PJ, Zucha B, AtKins L. Leading the flock: organ donation feelings, beliefs, and intentions among African American clergy and community residents. Prog Transplant 2005: 15: 211.

7. Boulware Le, Cooper LA, Ratner LE, LaVeist TA, Powe NR. Race and trust in the health care system. Public Health Rep 2003: 118: 358.

8. Boulware Le, Ratner LE, Cooper LA, Sosa JA, LAVeist TA, Powe NR. Understanding disparities in donor behavior: race and gender differences in willingness to donate blood and cadaveric organs. Med Care 2002: 40: 85.

9. Zaramo Ce, Morton T, Yoo JW, Bowen GR, Modlin CS. Culturally competent methods to promote organ donation rates among African-Americans using venues of the Bureau of Motor Vehicles. Transplant Proc 2008: 40: 1001.

10. Callender CO, Miles PV, Hall MB. National MotTEP: educating to prevent the need for transplantation. Minority Organ Tissue Transplant Education Program. Ethn Dis 2002: 12: S1-34-7.

11. Miles P, Callender CO. Community education and empowerment key to increased minority donation rates. Transplant Proc 1997: 29: 3756.

12. Callender CO, Washington AW. Organ/tissue donation the problem! Education the solution: a review. J Natl Med Assoc 1997: 89: 689.

13. Rodrigue JR, Cornell DL, Howard RJ. Relationship of exposure to organ donation information to attitudes, beliefs, and donation decisions of next of kin. Prog Transplant 2009: 19: 173.

14. Alvaro EM, Siegel JT, Turcotte D, Lisha N, Crano WD, Dominick A. Living kidney donation among Hispanics: a qualitative examination of barriers and opportunities. Prog Transplant 2008: 18: 243.

15. Albright Cl, Glanz K, Wong L, Dela Cruz Mr, Abe L, SAgayadoro TL. Knowledge and attitudes about deceased donor organ donation in Filipinos: a qualitative assessment. Transplant Proc 2005: 37: 4153.

16. Siminoff LA, Burant C, Youngner SJ. Death and organ procurement: public beliefs and attitudes. Soc Sci Med 2004: 59: 2325.

17. Pham H, Spigner C. Knowledge and opinions about organ donation and transplantation among Vietnamese Americans in Seattle, Washington: a pilot study. Clin Transplant 2004: 18: 707.

18. Arab American Institute. Arab Americans. Washington, DC: Arab American Institute, 2002.

19. Suleiman MW. Arabs in America: Building a New Future. Philadelphia: Temple University Press, 1999.

20. El-Sayed AM, Galea S. The health of Arab-Americans living in the United States: a systematic review of the literature. BMC Public Health 2009: 9: 272.

21. Mathur AK, Sonnenday CJ, Merion RM. Race and ethnicity in access to and outcomes of liver transplantation: a critical literature review. Am J Transplant 2009: 9: 2662.

22. Tuttle-Newhall JE, Krishnan SM, Levy MF, MCBride V, Orlowski JP, Sung RS. Organ donation and utilization in the United States: 1998-2007. Am J Transplant 2009: 9(4 Pt 2): 879 .

23. Dallo FJ, James SA. Acculturation and blood pressure in a community-based sample of Chaldean-American women. J Immigr Health 2000: 2: 145.

24. Dallo FJ, Borrell LN. Self-reported diabetes and hypertension among Arab Americans in the United States. Ethn Dis 2006: 16: 699. 
25. Jamil H, FAkhouri M, Dallo F, Templin T, Khoury R, FAKHOURI H. Self-reported heart disease among Arab and Chaldean American women residing in southeast Michigan. Ethn Dis 2008: 18: 19.

26. Hatahet W, Khosla P, Fungwe TV. Prevalence of risk factors to coronary heart disease in an Arab-American population in southeast Michigan. Int J Food Sci Nutr 2002: 53: 325.

27. Schwartz KL, Kulwicki A, Weiss LK et al. Cancer among Arab Americans in the metropolitan Detroit area. Ethn Dis 2004: 14: 141.

28. Schaeffner ES, Windisch W, Freidel K, Breitenfeldt $\mathrm{K}$, WinKelmayer WC. Knowledge and attitude regarding organ donation among medical students and physicians. Transplantation 2004: 77: 1714.

29. Shaheen FAM, Al-Jondeby M, Kurpad R, Al-Khader AA. Social and cultural issues in organ transplantation in Islamic countries. Ann Transplant 2004: 9: 11.

30. Shaheen FAM, Souqiyyeh MZ. Increasing organ donation rates from Muslim donors: lessons from a successful model. Transpl Proc 2004: 36: 1878.

31. Shaheen Fam, Sougiyyeh MZ, Al-Attar B, Jaralla A, SwAILEM ARA. Survey of opinion of secondary school students on organ donation. Saudi J Kidney Dis Transpl 1996: 7: 131.

32. Rachmani R, Mizrahi S, Agabaria R. Attitudes of Negev Beduins toward organ donation: a field survey. Transpl Proc 2000: 32: 757.

33. Kececioglu N, Tuncer M, Yucetin L, Akaydin M, YAKUPOGLU G. Attitudes of religious people in Turkey regarding organ donation and transplantation. Transpl Proc 2000: 32: 629.

34. Hassoun RJ. Arab Americans in Michigan. East Lansing: Michigan State University Press, 2005.

35. Baker W, Stockton R, Howell S et al. Detroit Arab American Study. October 25, 2006. Ann Arbor, MI: InterUniversity Consortium for Political and Social Research, 2003.

36. Al-Shehri S, Shaheen FA, Al-Khader AA. Organ donations from deceased persons in the Saudi Arabian population. Exp Clin Transplant 2005: 3: 301.

37. Al-FAQIH SR. The influence of Islamic views on public attitudes towards kidney transplant donation in a Saudi Arabian community. Public Health 1991: 105: 161.

38. El-Shoubaki H, Bener A. Public knowledge and attitudes toward organ donation and transplantation: a crosscultural study. Transpl Proc 2005: 37: 1993.

39. AlKhawari FS, Stimson GV, Warrens AN. Attitudes toward transplantation in U.K. Muslim Indo-Asians in West London. Am J Transplant 2005: 5: 1326.

40. Bener A, El-Shoubaki H, Al-Maslamani Y. Do we need to maximize the knowledge and attitude level of physicians and nurses toward organ donation and transplant? Exp Clin Transplant 2008: 6: 249.

41. El-Shahat YIM. Islamic viewpoint of organ transplantation. Transpl Proc 1999: 31: 3271.

42. Syed J. Islamic views on organ donation. J Transplant Coord 1998: 8: 157.

43. AL-KAWTHARI MIA. Organ donation and transplantation. Darul Iftaa, Leicester, UK, 2004.

44. Spigner C, Weaver M, Cardenas V, Allen MD. Organ donation and transplantation: ethnic differences in knowledge and opinions among urban high school students. Ethn Health 2002: 7: 87.

45. MocAn N, TeKin E. The determinants of the willingness to donate an organ among young adults: evidence from the
United States and the European Union. Soc Sci Med 2007: 65: 2527.

46. Clemens J, Couper M, Powers K. The Detroit Area Study: Celebrating 50 Years. Ann Arbor: University of Michigan, 2002.

47. Padela Ai, Heisler M. The association of perceived abuse and discrimination after September 11, 2001, with psychological distress, level of happiness, and health status among Arab Americans. Am J Public Health 2010: 100: 284.

48. Abdulrahim S, Baker W. Differences in self-rated health by immigrant status and language preference among Arab Americans in the Detroit Metropolitan Area. Soc Sci Med 2009: 68: 2097.

49. IDLER EL, KASL S. Health perceptions and survival: do global evaluations of health status really predict mortality? J Gerontol 1991: 46: S55.

50. WARE JE JR. Improvements in short-form measures of health status: introduction to a series. J Clin Epidemiol 2008: 61: 1.

51. Grande ED, Taylor A, Wilson D. South Australian Health and Wellbeing Survey. South Australia: Population Research and Outcome Studies Unit, Department of Health, 2002.

52. Salyers MP, Bosworth HB, Swanson JW, Lamb-Pagone J, OSHER FC. Reliability and validity of the SF-12 health survey among people with severe mental illness. Med Care 2000: 38: 1141 .

53. Goldberg D, Williams P. A User's Guide to the General Health Questionnaire. Windsor: NFER-Nelson, 1988.

54. Cairney J, Veldhuizen S, Wade T, Kurdyak P, STREINER D. Evaluation of 2 measures of psychological distress as screeners for depression in the general population. Can J Psychiatry 2007: 52: 111.

55. Rubin DB. Multiple Imputation for Nonresponse in Surveys. New York: Wiley, 1987.

56. Matsudaira T. Measures of psychological acculturation: a review. Transcult Psychiatry 2006: 43: 462.

57. Alvaro EM, Jones SP, Robles AS, Siegel JT. Predictors of organ donation behavior among Hispanic Americans. Prog Transplant 2005: 15: 149.

58. VATHSAla A. Improving cadaveric organ donation rates in kidney and liver transplantation in Asia. Transplant Proc 2004: 36: 1873.

59. LAM WA, MCCullough LB. Influence of religious and spiritual values on the willingness of Chinese-Americans to donate organs for transplantation. Clin Transplant 2000: 14: 449.

60. Yuen CC, Burton W, Chiraseveenuprapund P et al. Attitudes and beliefs about organ donation among different racial groups. J Natl Med Assoc 1998: 90: 13.

61. Shaheen FAM, Souqiyyeh MZ, Ramprassad K, Attar MB. Current issues and problems of transplantation in the Middle East: the Arabian Gulf. Transpl Proc 2001: 33: 2621.

62. Shaheen FAM, Souqiyyeh MZ. How to improve organ donation in the MESOT countries. Ann Transplant 2004: 9: 19.

63. Jotкowitz A. New models for increasing donor awareness: the role of religion. Am J Bioeth 2004: 4: 41; discussion W35-7.

64. Callender CO, Hall mB, Branch D. An assessment of the effectiveness of the Mottep model for increasing donation rates and preventing the need for transplantation - adult findings: program years 1998 and 1999. Semin Nephrol 2001: 21: 419.

65. Shah SM, Ayash C, Pharaon NA, Gany FM. Arab American immigrants in New York: health care and cancer knowledge, attitudes, and beliefs. J Immigr Minor Health 2008: 10: 429. 
Padela et al.

66. Callender CO. Organ donation in blacks: a community approach. Transplant Proc 1987: 19(1 Pt 2): 1551.

67. Boulware LE, Ratner LE, Sosa JA, Cooper LA, LaVeist TA, Powe NR. Determinants of willingness to donate living related and cadaveric organs: identifying opportunities for intervention. Transplantation 2002: 73: 1683.

68. University of Michigan News Service. U-M Detroit Arab American Study Portrays a Complex Population. Ann Arbor: University of Michigan News Service, 2004.

69. The Detroit Arab American Community. In: Detroit A ed. Dearborn, MI: David Communications, 2010.

70. Rodriguez-Villar C, Paredes D, Ruiz A et al. Attitude of health professionals toward cadaveric tissue donation. Transpl Proc 2009: 41: 2064.

71. Hobeika MJ, Simon R, Malik R et al. US surgeon and medical student attitudes toward organ donation. J Trauma Inj Infect Crit Care 2009: 67: 372.

72. Rios A, Ramirez P, Galindo PJ et al. Primary health care personnel faced with cadaveric organ donation: a multicenter study in south-eastern Spain. Clin Transpl 2008: 22: 657.

73. Pelleriaux B, Roels L, Van Deynse D, Smits J, Cornu O, Delloye C. An analysis of critical care staff's attitudes to donation in a country with presumed-consent legislation. Prog Transplant 2008: 18: 173.

74. Feeley TH, Tamburlin J, Vincent DE. An educational intervention on organ and tissue donation for first-year medical students. Prog Transplant 2008: 18: 103.

75. Cohen J, Ben Ami S, Ashrenazi T, Singer P. Attitude of health care professionals to brain death: influence on the organ donation process. Clin Transpl 2008: 22: 211.

76. Chernenko SM, Jensen L, Newburn-Cook C, Bigam DL. Organ donation and transplantation: a survey of critical care health professionals in nontransplant hospitals. Prog Transplant 2005: 15: 69.

77. Williams MA, Lipsett PA, Rushton $\mathrm{CH}$ et al. The physician's role in discussing organ donation with families. Crit Care Med 2003: 31: 1568. 